\title{
Grade Inflation: Causes, Consequences and Cure
}

\author{
Faieza Chowdhury ${ }^{1}$ \\ ${ }^{1}$ School of Business Studies, Southeast University, Dhaka, Bangladesh \\ Correspondence: Faieza Chowdhury, Southeast University, Banani, Dhaka 1213, Bangladesh.
}

$\begin{aligned} & \text { Received: December 11, } 2017 \\ & \text { Accepted: July 23, } 2018 \quad \text { Online Published: September 6, } 2018 \\ & \text { doi:10.5539/jel.v7n6p86 }\end{aligned}$ URL: https://doi.org/10.5539/jel.v7n6p86

\begin{abstract}
Academic institutions worldwide, from primary schools to universities, use grades or marks as a fundamental sorting and signaling mechanism for students. The grades awarded to students should be indicative of learning outcomes. However, do the grades awarded today accurately reflect student achievement in the classroom? Grade inflation has become a widespread phenomenon within the education system in the past thirty years, garnering massive condemnation among educators, researchers and the public. Some people even view grade inflation as a scandal, an injustice and a violation of student trust. Nevertheless, there are some academic institutions that find it convenient to ignore this problem and, in some cases, encourage the practice. In this paper, we examine the various factors that can contribute to grade inflation. Additionally, we assess how grade inflation can create problems for students, faculty, and society as a whole. Finally, we provide some suggestions and recommendations to solve the problems of grade inflation.
\end{abstract}

Keywords: education, grade inflation, student assessment, student performance

\section{Introduction}

The term 'grade inflation' denotes an increase in grade point average (GPA) without a concomitant increase in achievement (Potter \& Nyman, 2001). According to Eiszler (2002), grade inflation is the "student attainment of higher grades independent of increased levels of academic attainment". Therefore, grade inflation simply means that students are given higher marks without demonstrating higher levels of mastery. Grade inflation can lead to a compression of grades toward the top of the scale; therefore, the term 'grade compression' is also used to express grade inflation. Some researchers have indicated that grade inflation is a symptom of a damaged grading system. Grade inflation may put a larger number of students at the top of the grade distribution curve in a particular class. In the absence of any grade inflation, an outstanding student would be awarded an ' $\mathrm{A}+$ ' grade, while a good student would receive a ' $\mathrm{B}+$ ' grade. However, if the grades are inflated by the class instructor, then both students may receive the same grade, making it difficult to differentiate their abilities.

Grade inflation has become the norm in many colleges and universities around the world. The grade point averages of students have increased in the last 30 years. Nevertheless, this subject is rarely discussed in academia, as it is a controversial issue. Even though most academic institutions are aware of the dangers of grade inflation, the problem is typically overlooked. According to Franklin, Theall, and Ludlow (1991), grade inflation is a trend that is out of control. Grade inflation is a global phenomenon, and previous studies indicate a steady rise in high grades being assigned to students in schools, colleges and universities. A wide range of countries have documented that the majority of academic institutions are awarding higher grades to current students for the same level of work compared to their predecessors. In UK universities, the number of firsts and 2:1s has increased in the past 10 years (Coughlan, 2014). Similarly, high school grades in the United States have increased by as much as $12.5 \%$ between 1991 and 2003 (ACT, 2005). Similar increases in top marks and grades have been documented in Canada, France, and Sweden, among many other countries (Alphonso, 2014; Bamat, 2014; Maagan \& Shapira, 2013; Wikstrom \& Wikstrom, 2005). By examining this phenomenon from a different angle, not only have the grade point averages increased but also the proportion of high grades awarded to students. This would be a great achievement if we truly believe that the rising grade averages of students in academic institutions reflect an increase in student learning. However, most educators today agree that the escalation of grade point averages is not due to increased learning or an increase in students' knowledge and skills. If grades are a form of academic currency, then grade inflation results in the devaluation of that currency. Grade inflation erodes confidence in the whole system of academic evaluation, devaluing all grades and even the degrees to which they lead (Juola, 1976; Pressley, 1976). 
According to Boretz (2004), accepting grade inflation as a practice damages the academic ethos. In academic institutions, student proficiencies and competencies are the most important outcomes in the teaching-learning process. However, the practice of grade inflation converts grades to currencies that are exchanged for enrollment in a particular institution. Although no single institution or educator can do anything to combat a culture of grade inflation, students may suffer significant harm if appropriate actions are not taken to curb this practice.

Some researchers have provided strong evidence regarding the negative consequences of grade inflation, but few strategies have been developed by the appropriate parties to resolve this problem. Some institutions even encourage the practice of grade inflation, ignoring the problem altogether. To understand the dilemma caused by grade inflation at academic institutions, the author read numerous research reports and articles focusing on the grading practices in different countries. Since this is a philosophical paper, the focus is on normative analysis of grade inflation, rather than an empirical analysis. There are numerous philosophical papers on grading, but very few have addressed the causes of grade inflation and even fewer have provided solutions to combat the problem. Our purpose in this paper is to map out the various aspects of grade inflation. We begin by explaining why various agents such as educators, academic institutions and the public engage in the practice of grade inflation. Then, we examine the various consequences of grade inflation and conclude by presenting some simple steps that academic institutions can take to resolve the problem of grade inflation.

\section{The Causes of Grade Inflation}

This section will address why different agents, such as educators, institutions and even the system, may engage in grade inflation. After analyzing the available literature on the topic of grade inflation, we have identified some specific causes for grade inflation.

\subsection{Why Do Educators Engage in Grade Inflation}

Nearly all academic institutions evaluate the performance of course instructors through student feedback. Faculty evaluations are conducted numerically by scoring various components that indicate how the instructor performed in comparison with his or her peers or the department as a whole. In most cases, student evaluations has a major role in assessing the instructors' teaching effectiveness and other decisions regarding contract renewals, promotions, tenure and teaching awards. Therefore, the desire for job security and financial benefits may encourage some instructors to practice grade inflation. Students also tend to gravitate toward instructors who inflate grades and away from those who do not, making the classes of instructors awarding higher grades fill up more rapidly. In some cases, this may lead to fewer students in the classes of instructors who grade honestly, which can possibly lead to a reduction in their pay for the course undertaken. Some faculty members may also frequently engage in grade inflation to save time. Typically, these are teachers who resist giving low grades to students because they do not want to spend most of their office hours giving justifications for low grades on assignments or examinations. Hence, to avoid such situations with their students, some faculty members simply award high grades.

The problem of grade inflation is exacerbated by the rise in the number of part-time faculty members, whose job security and compensation may vary by semester. According to Brian (1998), temporary and part-time teachers lack both the opportunity and the incentive to assume appropriate responsibility for the general academic development of their students. The non-tenured faculty members are more likely to give higher grades to students than their tenured counterparts to ensure strong evaluation ratings for their teaching. Therefore, non-tenured faculty members may rely on positive course evaluations to ensure continued employment, which motivates them to inflate grades (Boretz, 2004).

Moreover, instructors may also practice grade inflation due to concern for their students' psychology, motivation and life prospects. Some educators admit that students today face excessive parental and social pressures to achieve high grades. Under such circumstances, teachers may decide that grade inflation is preferable to causing deep psychological harm to students or preventing them from attaining their future prospects. In this respect, grade inflation may be perceived by some teachers as a personal expression of care toward their students (Finefter-Rosenbluh \& Levinson, 2015).

\subsection{Why Institutions Engage in Grade Inflation}

Academic institutions are enrollment-driven and every semester they face enormous pressure to enroll more students. Today greater competition for student enrollment between and within institutions is a prime factor for grade inflation. If students are not awarded high grades in a particular university, then they will transfer to another university where high grades are easily awarded. Universities that have financial constraints are more likely to inflate grades in order to attract more students. A study of 544 academic institutions revealed that $77 \%$ 
of these institutions adopted some form of innovation in their grading system. These changes in grading policy have led to a rise in grade point averages (Collins \& Nickel, 1975). An increase in grade point averages was also reported by the American Academy of Arts and Sciences, which summarized the findings of several studies involving 180 universities and surveys of over 50,000 students (Rosovsky \& Hartley, 2002).

Moreover, most academic institutions believe in the customer-based concept that "we are here to serve and please customers". Some researchers, such as Brian (1998), state that as the cost of education has increased, students have been led to expect a greater value for the money that they spent on their education. Consequently, pressure exists on academic institutions to deliver grades that will satisfy students and parents, regardless of whether or not the standards of excellence are met.

Most academic institutions subscribe to the myth that high grades and success are closely linked, particularly in terms of future success. By awarding high grades to the students, academic institutions often try to give signals to admissions officers and potential employers that their students are comparatively better than others. Therefore, grades are often used as a tool by the academic institutions to gain a strong foothold in the competitive marketplace.

\subsection{Why the System Engages in Grade Inflation}

The educational system, whether it is at the district, the state or the national level, may decide to inflate students' grades for two main reasons: (1) to enhance the accessibility of education and future job prospects and (2) to maintain a positive public image. Occasionally, state administrators have incentive to inflate test scores across public board examinations in order to achieve high passing rates among the students. Administrators may even change the grading system or the assessment rules so that failure rates decline and more students achieve higher marks on board exams. This can encourage state administrators to set lower passing scores on state exams so that a larger number of students will pass the exams rather than fail.

Moreover, the notion of 'equal opportunity for all' can also encourage the system to implement strict grading structures. This is due to the concern that if educators practice strict grading for board exams, then there is the possibility that a large number of students could fail the exams and potentially lose out on opportunities in higher education and the workplace. Nevertheless, we must understand that grade inflation will not resolve social inequalities, just as printing more money will not alleviate poverty. At the national level, grade inflation is a negative-sum situation that imposes serious costs on society.

\section{The Consequences of Grade Inflation}

This section presents three different potential victims of grade inflation: the students, the academic institutions and society as a whole.

\subsection{How Students Are Affected}

Grade inflation may mislead students regarding their actual degree of academic performance. If teachers award higher grades to students than what they actually deserve, then the students will misunderstand their own capabilities. The students may believe that they are well-prepared to succeed at endeavors for which they have insufficient knowledge and skills.

Grade inflation may also result in grade compression, where higher grades are awarded for average or even relatively poor performance. Grade compression is mainly unfair to the best students in the class, who may have to share the same good grades with less hardworking classmates (Finefter-Rosenbluh \& Levinson, 2015). Therefore, this may discourage the hardworking students from achieving their full potential. Grade inflation therefore promotes mediocrity by giving less-qualified students more than they deserve, diminishing student effort and achievement (Lackey \& Lackey, 2006).

Another problem is that grade inflation can deteriorate the work ethic of students. If high grades are awarded easily, then students may believe that they do not need to work as much to achieve high grades. Students may also carry this attitude into subsequent classes. In the case of prerequisite courses, students may have a false sense of mastery regarding that course. This can create problems, as the student may find it difficult to do well in the advanced courses due to a lack of adequate knowledge on the prerequisite course.

Grade inflation may influence the course selection process of the students. Students often quickly identify teachers who practice grade inflation and attempt to select their classes. Some students may even postpone taking certain courses until they are taught by instructors who practice grade inflation (Stanoyevitch, 2008). Grade inflation may also encourage students to select subjects or majors where they can easily obtain higher grades. 


\subsection{How Institutions Are Affected}

Grade inflation may have a negative impact on institutions such as schools, universities and potential employers. The reliability of grades is vital in employment, scholarship and admission-related decisions. Students who graduate must have a GPA higher than a certain threshold in order to obtain opportunities in the labor market or access higher education. Due to grade inflation, transcripts and other similar documents that provide academic proof of credentials may lose some of their value.

Krautmann and Sander (1999) assert that grade inflation dilutes the role of educational credentials when screening workers in the labor market. In the labor market, grades are an indicator of the candidate's level of knowledge, skills and achievement in a particular subject or field. Grades are also used by potential employers to assess a candidate's learning capability and attitude toward work. If employers believe that a certain school or university engages in grade inflation, the value of a $4.0 \mathrm{GPA}$ will not carry the same weight as it should. Employers cannot use these grades to make meaningful distinctions among job applicants while conducting any hiring decisions, as inflated grades do not reflect whether the candidate actually has the knowledge and skills required for the job.

Grades are also used by admission officers to award admissions or scholarships within and across universities. Grade inflation may lead to less qualified students enrolling in respectable institutions, which can later harm the reputation of these institutions. Therefore, grade inflation causes grades to fail their positive functions ofproviding feedback on student performance, motivating students, guiding them in future decisions and providing a basis for recruitment and enrollment decisions.

Moreover, grade inflation can have a negative impact on the academic standing of schools and universities, as their degrees will have less value in the market. Schools and universities that practice grade inflation may be classified as "grade sellers" and at some point, their graduates may become less marketable.

\subsection{How Society Is Affected}

Grade inflation may increase social disparities and inequalities, as students who can afford to attend schools or universities that award comparatively higher grades will achieve unearned advantages in college and graduate admissions. Due to inflated grades, these students also may have better opportunities in the job market, which enhances social disparity and socioeconomic inequality. Schools are the primary institutions for credentialing students. Grades enable young people to gain or lose access to further education, as well as vocational and career opportunities. In an impartial society, academic institutions would be structured in a manner that prevents inequality in grading practices, which is the opposite of what is currently happening.

\section{Recommendations}

After reading numerous papers on grade inflation, we have concluded that it is crucial for the respective authoroties to take corrective actions inorder to attain positive changes in the grading process. In some cases, the most difficult task would be to convince the respective authorities that grade inflation is a problem and that actions are needed to mitigate it. In this section, we present some easy steps that can be taken by university administration and department chairs to prevent grade inflation.

\subsection{Resource Allocation to Academic Units Should Not Be Based Solely on Student Enrollment}

The motivation for grade inflation within and across departments often stems from the fact that university resources are directly linked to increased enrollment in each department or school. According to Butler (1975), grades have become a tool in the increasingly aggressive competition for enrollment. Often there is a tremendous pressure on deans and department chairs to increase student enrollment. Hence, they may engage in grade inflation to achieve higher enrollment. Since enrollment patterns in a particular department or school can fluctuate for various reasons, such as market trends, parental pressure or personal preferences, we propose that student enrollment should not be the only criteria used for decisions regarding resource allocation.

Low student enrollment may also influence the grading behavior of the course instructors. In some academic institutions, classes with only a few students enrolled will be cancelled by the administration, or the faculty member will not receive full payment for teaching the course. This can motivate faculty members to practice grade inflation so that their class does not get cancelled, as they realize that students are attracted to instructors that are easy graders. To prevent this situation, it is important for the university administration to realize that certain courses may have low enrollments due to legitimate reasons, such as poor timing, required prerequisites, 
or course syllabus difficulty. In this case, the faculty members should not be penalized for low student enrollment.

\subsection{Institutions Should Use a Balanced Method to Evaluate Faculties}

Teachers are often evaluated by a student evaluation system, but this technique does not often reflect how rigorous the courses are or what standards of teaching the teachers use in the class. The faculty evaluation forms generally reflect how popular the teachers are with the students. By engaging in these popularity contests, the faculty members often decrease the level of academic rigor in their courses, which is a prime symptom of grade inflation. To overcome this problem, it is important that faculty evaluations be more transparent. To empower faculty members to increase the rigor of course content and apply fair grading practices, faculty evaluations need to be more diversified. The faculty member could be rated not only by students but by a senior member of his/her department. This will ensure that the student evaluation was not the only factor used to evaluate his/her performance every semester. This will also discourage the faculty members from inflating grades by either dropping the more difficult material from the course syllabus or grading more leniently.

It is unfortunate that in many institutions, an instructor's success rate is judged only by the student evaluation scores. This may encourage instructors to succumb to the lure of grade inflation. Therefore, another important factor would be to re-design the evaluation metrics so that greater emphasis is provided on faculty reviews and comments, instead of on the average evaluation rating of a particular course. If students are asked the right questions on the evaluation forms, then the students' comments will allow administrators to understand the rigor and academic standards of a course.

\subsection{Provide Instructor Training on Fair Student Assessment}

New faculty members or part-time faculty members, who are more likely to practice grade inflation, should be asked to attend mandatory workshops on fair grading practices. Senior faculty members who have been identified as being accomplished in the areas of rigorous grading and effective teaching may be sent to these workshops to mentor or train these new instructors. This will be instrumental in enhancing teaching effectiveness and reducing faculty defensiveness during evaluations.

\subsection{Educate the Students about Grading Policies}

Educators are often misguided in assuming that students understand the grading policies of the academic institution. Often, new students who enroll in a college or university learn about grading policies from their peers or senior classmates, who can mislead them. It is important for academic institutions and individual faculty members to clearly articulate the standards that are expected of their students. These statements of standards should also appear in the syllabi of their courses, so that students will understand what is expected of them and the grading policies that will be applied for assessment. Discussing grading policies and standards will help restore fair grading practices. This discussion will also help students to have realistic expectations about what grades they deserve based on the performance delivered. Furthermore, administrators must incorporate an obligatory session on the grading policies of the university during new student orientation programs. These orientation sessions should be led by a panel of faculty members and high-achieving student speakers who can discuss their experiences regarding challenging courses and their views regarding the grading system.

\subsection{Chair and Program Heads Should Hold Regular Meetings to Discuss Grading Trends}

The lack of accountability and scrutiny is another cause of grade inflation. In most cases, faculty members are not asked to justify the grades that they award to their students unless someone complains. Moreover, the faculty members are not held accountable for the rigor of their classes or what assessment tools they utilize in the class. The department chairs should hold meetings every semester to provide feedback to the faculty members on their teaching effectiveness and student assessment. If an instructor has provided a grade that deviates significantly from the departmental average, then he/she should be asked to justify the discrepancy and, if necessary, adjust his/her grading system. This will discourage faculty members from practicing grade inflation, as they will be held accountable for their grading practices.

In these meetings, the departmental chairs should provide each faculty members with performance statistics regarding his or her grade distribution summary, class mean GPAs, and a histogram of the assigned grades, alongside the departmental average. The GPA mean of every course should be included alongside the teaching evaluation score of the class to help identify any sign of grade inflation. Written policies and guidelines for grading should be distributed to all faculty members, including the part-time and adjunct instructors. 


\subsection{Use of the Quota System}

Restricting the number of high grades that instructors can award to their students in a particular class is another way to combat grade inflation. This approach was adopted by Princeton in 2004 when the administration provided guidelines to all faculty members stating that, on average, no more than $35 \%$ of the grades awarded in undergraduate courses should be in the ' $\mathrm{A}$ ' range.

Department chairs or heads can prepare comparative statistics every year to indicate how each department has reported its grade distribution compared to other departments. Based on the findings, the university administrators can create a policy for allocating a quota on the number of 'A's among their departments. However, the quota system has limitations, as it may prevent a fraction of the students from receiving the grades that they actually deserve. In less rigorous courses, a large number of students in the class may rightfully deserve an ' $A$ ' grade, but if the quota system is applied, some of these students will be unfairly penalized.

\section{Conclusion}

Most of the academic institutions that practice grade inflation believe in the notion of "student consumerism", which states that students want their money's worth and therefore want to obtain easy 'A' grades. Moreover, there is an innate obligation instilled in academic institutions to inflate grades to help their poorer-performing students to acquire better opportunities in the job market. However, it is important for these institutions to understand that, in the long run, the institution's reputation and student proficiencies are more important than individual grades. Nevertheless, some people believe that grade inflation is unavoidable as it is 'costless' to award good grades to the students. In this paper, we have discussed various negative consequences of grade inflation to prove that grade inflation is not really costless, as it can have a negative impact on graduates, potential employers, the reputation of academic institutions and the well-being of society.

In conclusion, after reading numerous papers that focus on grade inflation, we believe it is time to take constructive steps to solve this issue. It is important for academic institutions to begin the dialogue on grade inflation by first acknowledging that it is a serious problem that can have a variety of long term negative consequences. In this paper, we have provided six basic reform suggestions that can be adopted by academic institutions to alleviate the problem of grade inflation. It is our hope that this paper will create more awareness regarding grade inflation and stimulate further discussions in order to formulate new strategies to combat grade inflation.

\section{References}

ACT. (2005). Are high school grades inflated? Issues in college readiness. Retrieved from http://www.act.org/research/policymakers/pdf/issues.pdf

Alphonso, C. (2014, April 14). Citing grade inflation in high schools, elite program boosts its own marks. The Globe and Mail. Retrieved from http://www.theglobeandmail.com/news/national/education/elite-ibprogram-to-boost-marks-in-response-to-g rade-inflation/article17953433/

Bamat, J. (2014, July 7). Are French high school students getting smarter? France24.

Boretz, E. (2004). Grade Inflation and the Myth of Student Consumerism. Journal of College Teaching, 52(2), 42-46. https://doi.org/10.3200/CTCH.52.2.42-46

Brian, N. (1998). A proposal for Dealing with Grade Inflation: The Relative Performance Index. Journal of Education for Business, 40-43.

Butler, R. C. (1975). The grading game. Coll. Univ., 50(40), 733-739.

Collins, J. R., \& Nickel, K. N. (1975). Grading policies in higher education: the Kansas Study/ the National survey. University Studies, 103, Wichita.

Coughlan, S. (2014, January 21). University grade inflation disputed. BBC News. Retrieved from http://www.bbc.com/news/education-25811702

Eiszler, C. F. (2002). College Students' Evaluations of Teaching and Grade inflation. Research in Higher Education, 43(4), 483-501. https://doi.org/10.1023/A:1015579817194

Finefter-Rosenbluh, I., \& Levinson, M. (2015). What is wrong with grade inflation (if anything)? Philosophical Inquiry in Education, 23(1), 3-21.

Franklin, J., Theall, M., \& Ludlow, L. (1991). Grade inflation and student ratings: A closer look. Paper presented at the annual meeting of the American Educational Research Association, Chicago. 
Juola, A. E. (1976). Grade Inflation- 1975: is it over? Mimeo. Office of Learning and Evaluation Services. Michigan State University.

Krautmann, A. C., \& Sander, W. (1999). Grades and student evaluations of teachers. Economic of Education Review, 18, 59-63. https://doi.org/10.1016/S0272-7757(98)00004-1

Lackey, L. W., \& Lackey, W. J. (2006). Grade inflation: Potential Causes and Solutions. Int. J. Eng. Education, 22(1), 130-139.

Maagan, D., \& Shapira, L. (2013). Reconsidering grade inflation in Israel. Jerusalem, IL: Israeli Central Bureau of Statistics.

Pressley, M. (1976, Jan 21). Inflation hits the campus. Wall Street J, p. 16.

Rosovsky, H., \& Hartley, M. (2002). Evaluation and the Academy: Are we doing the right thing? Grade inflation and letters of recommendation, American Academy of Arts and Sciences, Cambridge, Massachusetts.

Stanoyevitch, A. (2008). Controlling grade inflation. Retrieved from ERIC database.

Wikström, C., \& Wikström, M. (2005). Grade inflation and school competition: An empirical analysis based on the Swedish upper Secondary schools. Economics of Education Review, 24(3), 309-322. https://doi.org/10.1016/j.econedurev.2004.04.010

William, P., \& Nyman, M. (2001). Be careful what you wish for: Analysis of Grading trends at a small liberal arts College. College and University: The Journal of the American Association of Collegiate Registrars, 76(4), 9-14.

\section{Copyrights}

Copyright for this article is retained by the author, with first publication rights granted to the journal.

This is an open-access article distributed under the terms and conditions of the Creative Commons Attribution license (http://creativecommons.org/licenses/by/4.0/). 